\title{
Internal Controls for Quantitative Polymerase Chain Reaction of Swine Mammary Glands During Pregnancy and Lactation
}

\author{
S. Tramontana, ${ }^{*}$ M. Bionaz, $†$ A. Sharma,§ D. E. Graugnard, $† \ddagger$ E. A. Cutler, $\dagger^{1}$ P. Ajmone-Marsan, ${ }^{*}$ \\ W. L. Hurley, $†$ and J. J. Loor $\ddagger^{2}$ \\ *Istituto di Zootecnica, Università Cattolica del Sacro Cuore, 29100 Piacenza, Italy \\ †Mammalian NutriPhysioGenomics, Department of Animal Sciences, University of Illinois, Urbana 61801 \\ $\ddagger$ Division of Nutritional Sciences, University of Illinois, Urbana 61801 \\ §Animal Genetics Division, Indian Veterinary Research Institute, Izatnagar, Bareilly, Uttar Pradesh-243122, India
}

\section{ABSTRACT}

High-throughput microarray analysis is an efficient means of obtaining a genome-wide view of transcript profiles across physiological states. However, quantitative PCR (qPCR) remains the chosen method for highprecision mRNA abundance analysis. Essential for reliability of qPCR data is normalization using appropriate internal control genes (ICG), which is now, more than ever before, a fundamental step for accurate gene expression profiling. We mined mammary tissue microarray data on $>13,000$ genes at $-34,-14,0,7,14$, 21 , and $28 \mathrm{~d}$ relative to parturition in 27 crossbred primiparous gilts to identify suitable ICG. Initial analysis revealed TBK1, PCSK2, PTBP1, API5, VAPB, QTRT1, TRIM41, TMEM24, PPP2R5B, and AP1S1 as the most stable genes (sample/reference $=1 \pm 0.2$ ). We also included 9 genes previously identified as ICG in bovine mammary tissue. Gene network analysis of the 19 genes identified AP1S1, API5, MTG1, VAPB, TRIM41, MRPL39, and RPS15A as having no known co-regulation. In addition, $U X T$ and $A C T B$ were added to this list, and mRNA abundance of these 9 genes was measured by qPCR. Expression of all 9 of these genes was decreased markedly during lactation. In a previous study with bovine mammary tissue, mRNA of stably expressed genes decreased during lactation due to a dilution effect brought about by large increases in expression of highly abundant genes. To verify this effect, highly abundant mammary genes such as CSN1S2, $S C D, F A B P 3$, and $L T F$ were evaluated by qPCR. The tested ICG had a negative correlation with these genes, demonstrating a dilution effect in the porcine mammary tissue. Gene stability analysis identified API5, $V A B P$, and MRPL39 as the most stable ICG in porcine

Received March 10, 2008.

Accepted April 12, 2008.

${ }^{1}$ Current address: 1383 Deerfield Dr., Allentown, PA 18104.

${ }^{2}$ Corresponding author: jloor@uiuc.edu mammary tissue and indicated that the use of those 3 genes was most appropriate for calculating a normalization factor. Overall, results underscore the importance of proper validation of internal controls for qPCR and highlight the limitations of using absence of time effects as the criteria for selection of appropriate ICG. Further, we showed that use of the same ICG from one organism might not be suitable for $\mathrm{qPCR}$ normalization in other species.

Key words: internal control gene, quantitative polymerase chain reaction

\section{INTRODUCTION}

Quantitative reverse transcription PCR is the method of choice for mRNA expression analysis of small number of genes and is commonly used for verification of microarray results. Although qPCR is an accurate technique, it is subject to errors during the steps from RNA extraction to mRNA quantitative analysis (Valasek and Repa, 2005). Normalization of qPCR data is required to take into account those errors, just as it is the case for traditional methods of mRNA quantification (e.g., Northern blot analysis, ribonuclease protection assay, competitive reverse transcription PCR). Genes that maintain a stable expression level (i.e., amount of mRNA/cell) regardless of the experimental condition, or cell and tissue type, are the most widely used internal control genes (ICG) for normalization, also referred as housekeeping genes (Vandesompele et al., 2002).

The classical approach for choosing ICG has been based solely on the absence of statistical effects of a treatment or physiological state on qPCR data. However, this approach is not ideal in studies in which a treatment or physiological adaptation is accompanied by large increases in constitutively abundant transcripts. In this scenario, the expression level of stably expressed genes will appear as downregulated (i.e., it is a dilution effect) and will render these genes unrelia- 
ble as ICG. Dilution effects often seen in metabolically active tissues such as mammary glands (Reinhardt and Horst, 1999; Bionaz and Loor, 2007) give rise to technical artifacts arising from the use of the same amount of starting RNA in each reaction. We recently demonstrated a dilution effect on 9 stably expressed genes in bovine mammary during lactation (Bionaz and Loor, 2007). We hypothesized that a similar situation occurs in porcine mammary gland. In support of this hypothesis, previous studies reported consistent increases of mammary RNA and RNA:DNA ratio between the end of pregnancy and the beginning of lactation in pigs (Hacker and Hill, 1972; Kensinger et al., 1982).

The use of pairwise ratio-stability comparison among several candidate genes (Vandesompele et al., 2002) was an appropriate method to select ICG in a longitudinal study of bovine mammary (Bionaz and Loor, 2007). The method effectively overcomes obvious limitations associated with a simple evaluation of time effects on gene expression and takes into account a potential dilution effect. The objective of this study was to select an appropriate set of ICG for normalization of qPCR data generated from longitudinal pig mammary gland gene expression studies.

\section{MATERIALS AND METHODS}

\section{Animals and Tissue Collection}

Mammary tissue from 4 crossbred primiparous gilts each on $-34,-14,7,14,21$, and $28 \mathrm{~d}$ relative to parturition (DIM) and from 3 gilts at 0 DIM was used (Hurley et al., 1991; Kim et al., 1999). Tissue was harvested and immediately frozen in liquid $\mathrm{N}_{2}$ and preserved at $-80^{\circ} \mathrm{C}$ until RNA extraction.

\section{RNA Extraction, RNA Quality Evaluation, qPCR, and Primer Design and Testing}

Total RNA from 0.4 to $1.4 \mathrm{~g}$ of tissue was extracted with ice-cold Trizol reagent (Invitrogen, Carlsbad, CA) as described previously (Loor et al., 2005). Quantity and purity of isolated RNA samples were analyzed with a NanoDrop ND-1000 spectrophotometer (NanoDrop Technologies, Wilmington, DE). The RNA quality was assessed using a 2100 Bioanalyzer (Agilent Technologies, Santa Clara, CA). Only samples $(\mathrm{n}=27)$ with an RNA integrity number of 5 to 9 (median of 8), a range considered appropriate for downstream expression analysis (Fleige and Pfaffl, 2006), were used. Genomic DNA was removed with DNase using RNeasy Mini Kit columns (Qiagen, Valencia, CA). A portion of the assessed RNA was diluted to $100 \mathrm{mg} / \mathrm{L}$ using DNaseRNase-free water before reverse transcription. Sufficient cDNA was prepared to run all selected genes.
Each cDNA was synthesized by reverse transcription PCR and cDNA used for qPCR as described previously (Bionaz and Loor, 2007). Each sample was run in triplicate, and a 6-point relative standard curve plus the nontemplate control were used. The 4-fold-dilution standard curve was made using cDNA from a pool RNA of all the samples. The reactions were performed in an ABI Prism 7900 HT SDS instrument (Applied Biosystems, Foster City, CA) using the following conditions: $2 \mathrm{~min}$ at $50^{\circ} \mathrm{C}, 10 \mathrm{~min}$ at $95^{\circ} \mathrm{C}, 40$ cycles of $15 \mathrm{~s}$ at $95^{\circ} \mathrm{C}$, and $1 \mathrm{~min}$ at $60^{\circ} \mathrm{C}$. The presence of a single PCR product was verified by the dissociation protocol using incremental temperatures to $95^{\circ} \mathrm{C}$ for $15 \mathrm{~s}$ plus $65^{\circ} \mathrm{C}$ for 15 s. Data were calculated with the 7900 HT Sequence Detection Systems Software (version 2.2.1, Applied Biosystems).

Primer Express 3.0 software (Applied Biosystems), optimized for use with Applied Biosystems qPCR Systems, was used for primer design using default features, except for the amplicon length, which was fixed at a minimum of $80 \mathrm{bp}$. Primers were designed across exon junctions when possible to avoid amplification of genomic DNA. The exon junctions were uncovered blasting the pig sequence against human genome (Genome Browser Gateway, 2008). Primers were aligned against publicly available sequences at the National Center for Biotechnology Information (2008) and University of California, Santa Cruz (Genome Browser Gateway, 2008). Before $q P C R$, primers were tested using the same protocol as for $\mathrm{qPCR}$ without the dissociation step in a $20-\mu \mathrm{L}$ reaction. Part of the PCR product was run in a $2 \%$ agarose gel stained with ethidium bromide to assess presence of the product to an expected size and absence of primer-dimer, and the rest was purified using Qiaquick PCR purification kit (Qiagen) and sent to sequence at the Core DNA Sequencing Facility of the Roy J. Carver Biotechnology Center at the University of Illinois, Urbana. Only primers with high specificity evaluated by a single band on agarose gel, absence of primer-dimer, amplification of the right $\mathrm{cDNA}$ verified by sequencing (Table 1), and a unique peak in the dissociation curve after $q \mathrm{PCR}$ reaction were used.

\section{Selection and Evaluation of ICG}

Porcine mammary microarray data (Tramontana et al., 2007) were mined to identify a set of potential ICG. Ten genes were chosen among the most stably expressed in this data set following these criteria: 1) only genes with median intensity of $3 \mathrm{SD}$ above background intensity were used; 2) filtered data were uploaded to GeneSpring GX software (Agilent Technologies) and normalized using Lowess; 3 ) only genes with expression $\geq 100$ (i.e., medium-large mRNA abundance) relative 
Table 1. Accession number, gene name, hybridization position, primer sequence, and amplicon size of primers used to analyze gene expression by qPCR

\begin{tabular}{|c|c|c|c|c|c|}
\hline Accession no. & Gene & Primer $^{1}$ & $\operatorname{Primer}^{2}\left(5^{\prime}-3^{\prime}\right)$ & $\begin{array}{l}\text { Amplicon } \\
\text { size (bp) }\end{array}$ & E-value $^{3}$ \\
\hline \multirow[t]{2}{*}{ DQ452569 } & \multirow[t]{2}{*}{$A C T B$} & F.120 & CTTCTGCCATTTTCETAGGACTTTT & \multirow[t]{2}{*}{120} & \multirow[t]{2}{*}{$1.00 \mathrm{E}-23$} \\
\hline & & R.239 & AACACCTAGTCAGAAAGGCAAACA & & \\
\hline \multirow[t]{2}{*}{ CV865977 } & \multirow[t]{2}{*}{$A P 1 S 1$} & F.171 & GGAGCTCATGCAGGTTGTTCT & \multirow[t]{2}{*}{100} & \multirow[t]{2}{*}{$2.00 \mathrm{E}-06$} \\
\hline & & R.270 & GTAGAGGCTGGCGTATCTCTTATAGAC & & \\
\hline \multirow[t]{2}{*}{ CV872150 } & \multirow[t]{2}{*}{ API5 } & F.196 & GCATTTTTAGTAGCATAGGCCCTTT & \multirow[t]{2}{*}{82} & \multirow[t]{2}{*}{$2.00 \mathrm{E}-10$} \\
\hline & & R.277 & AACTTGAGGGAAGATTAACTGTGGAA & & \\
\hline \multirow[t]{2}{*}{ NM_001004030 } & \multirow[t]{2}{*}{ CSN1S2 } & F.876 & ATGTTTGGAGAGGCCAAGACA & \multirow[t]{2}{*}{120} & \multirow[t]{2}{*}{$1.60 \mathrm{e}-27$} \\
\hline & & R.995 & AAACCACAGTACAAACCCAGTATGTT & & \\
\hline \multirow[t]{2}{*}{ AJ416019 } & \multirow[t]{2}{*}{ FABP3 } & F.229 & GATGACAGGAAGGTCAAGTCCATT & \multirow[t]{2}{*}{100} & \multirow[t]{2}{*}{$6.00 \mathrm{E}-12$} \\
\hline & & R.328 & CTAGTTCCCGAACAAGCGTTGT & & \\
\hline \multirow[t]{2}{*}{ AY306198 } & \multirow[t]{2}{*}{$L T F$} & F.1486 & TGCAAATTTGACGAATTCTTTAGTCA & \multirow[t]{2}{*}{100} & \multirow[t]{2}{*}{$1.00 \mathrm{E}-19$} \\
\hline & & R.1585 & TGTTCACGCCCTGGTCATT & & \\
\hline \multirow[t]{2}{*}{ AY610067 } & \multirow[t]{2}{*}{ MRPL39 } & F.600 & CAAAAGAGAACCTACATTCCTTCACA & \multirow[t]{2}{*}{100} & \multirow[t]{2}{*}{$4.00 \mathrm{E}-20$} \\
\hline & & R.699 & TCTAATGCCACTTTTGCTTCAACT & & \\
\hline \multirow[t]{2}{*}{ AK231290 } & \multirow[t]{2}{*}{ MTG1 } & F.270 & AGGAGCAGCAGAAAATTATGCAA & \multirow[t]{2}{*}{100} & \multirow[t]{2}{*}{$9.00 \mathrm{E}-16$} \\
\hline & & R.369 & GGGATGATCTGCTTGATATTTTCA & & \\
\hline \multirow[t]{2}{*}{ AK238842 } & RPS15A & F.444 & TGCCGAAAAGAGAGGCAAAC & 100 & $7.00 \mathrm{E}-24$ \\
\hline & & R.543 & TTCGCCAATGTAACCATGCTT & & \\
\hline NM_213781 & $S C D$ & F.805 & TGGTGATGTTCCAGAGGAGGTACTA & 120 & $2.00 \mathrm{E}-26$ \\
\hline & & R.924 & TGGCGACGAACAGGCTTT & & \\
\hline NM_033549 & TRIM41 & F.1432 & TGTGGTGTGCCGAGAATCC & 90 & $1.00 \mathrm{E}-11$ \\
\hline & & R.1521 & CCCTGCAGTTTGGCCTTGTA & & \\
\hline NM_153477.1 & $U X T$ & F.277 & GCGGGACTTGCGAAAAGT & 100 & $1.00 \mathrm{E}-19$ \\
\hline & & R.376 & AGCTTCCTGGAGTCGCTCAA & & \\
\hline NM_004738.3 & $V A P B$ & F.402 & TGAAGACTACAGCACCACGTAGGT & 100 & $4.00 \mathrm{E}-14$ \\
\hline & & R.501 & TCGAAAGGCTGTAACATCACAGATA & & \\
\hline
\end{tabular}

\footnotetext{
${ }^{1}$ Direction $\left(\mathrm{F}=\right.$ forward; $\mathrm{R}=$ reverse) and hybridization position for each primer $\left(5^{\prime}-3^{\prime}\right)$.

${ }^{2}$ Exon-exon junction in primer sequences are underlined.

${ }^{3}$ Results of PCR product sequencing were BLAST-searched against all known nucleotides in the NCBl database. The E-value is the score from global alignment of homology with the pig sequence deposited in $\mathrm{NCBl}$; the lower the E-value, the higher the significance. All amplicons hit the appropriate porcine sequence with high homology (low E-value).
}

fluorescent units were chosen; and 4) only genes with expression ratio $\sim 1.0$ between sample/reference (RNA mixture from 5 different porcine tissues not including porcine mammary at the different time points) in at least 30 out of 35 microarrays were used (Figure 1).

\section{Gene Stability Evaluation}

geNorm software (Vandesompele et al., 2002; geNorm, 2008) was used for assessing gene expression ratio stability of potential ICG following the pairwise comparison method. geNorm also helps determine the optimal number of ICG and calculates a normalization factor (NF) to be used for normalization. The pairwise comparison requires evaluation of multiple genes to select appropriate internal controls. For this reason, we also included in our analysis 9 ICG (ACTB, GAPDH, RPS23, RPS9, MTG1, ITGB4BP, MRPL39, RPS15A, and $U X T)$ previously tested in a longitudinal bovine mammary gland experiment (Bionaz and Loor, 2007). Critical for the use of the pairwise comparison method in selecting appropriate ICG is the absence of co-regulation [common upstream regulator factor(s) or direct regulation of transcript expression between gene products] among the genes tested (Vandesompele et al., 2002). Co-regulation was assessed using Ingenuity Pathways Analysis (Redwood City, CA). The qPCR data representing casein $\alpha_{\mathrm{S} 2}$ (CSN1S2), fatty acid-binding protein 3 (FABP3), lactotransferrin ( $(\boldsymbol{L T F})$, and stearoyl-CoA desaturase (SCD) were normalized using the NF calculated with the most stable genes among the ones tested.

\section{Statistical Analysis}

A MIXED model with repeated measures (release 8.0; SAS Inst. Inc.,Cary, NC) was used to evaluate the effect of time on raw (i.e., nonnormalized) and normalized mRNA abundance. Compound symmetry was the most suitable covariate structure for repeated-measures analysis. The model included the fixed effect of time $(-34,-14,0,7,14,21$, and 28 DIM) and the random effect of gilt. Statistical correlations among nonnormal- 


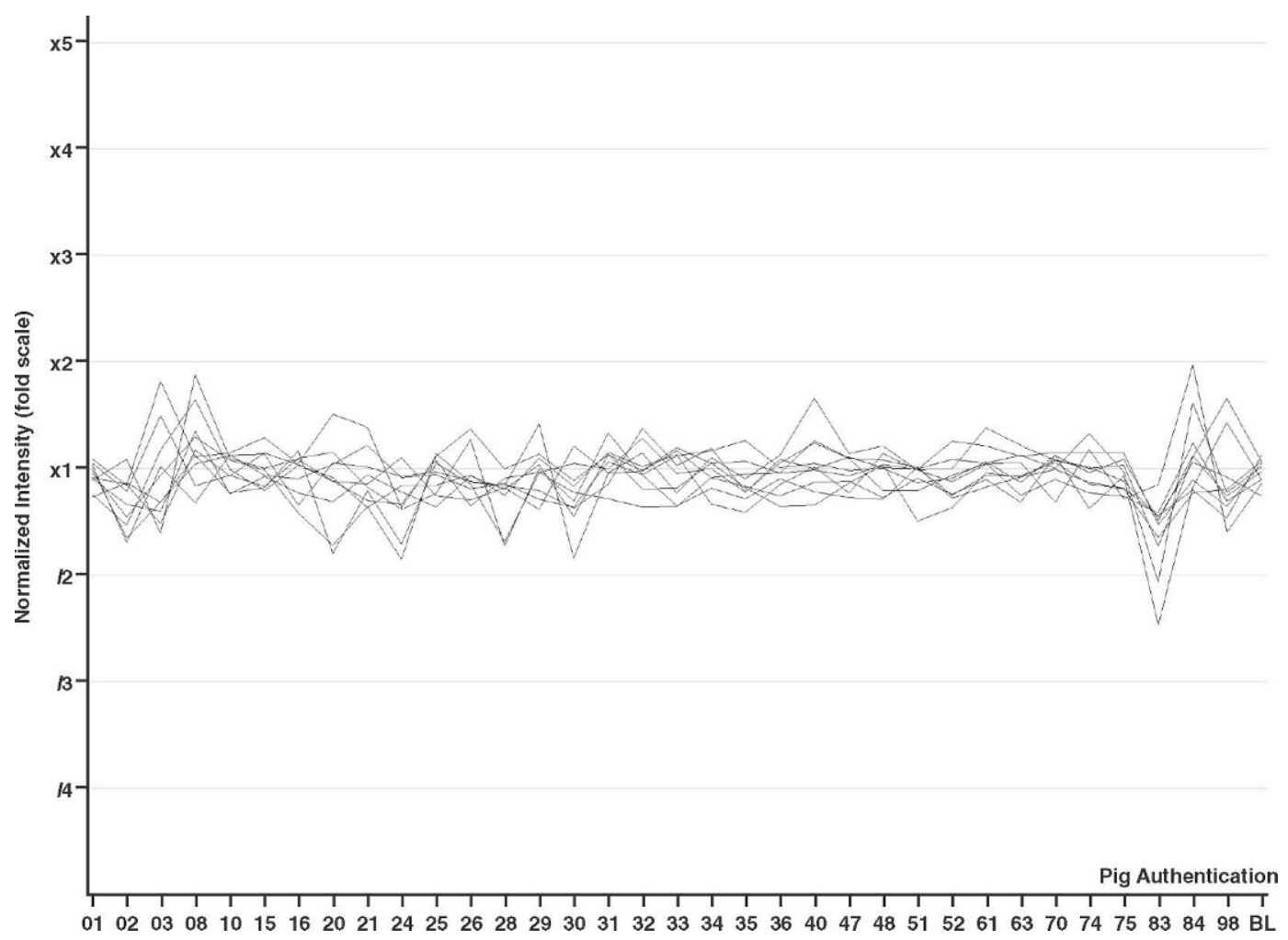

Figure 1. Expression ratio (sample/reference) for each single sample (i.e., gilt and time point) reported as $n$-fold for AP1S1, API5, PCSK2, $P P P 2 R 5 B, P T B P 1, Q T R T 1, T B K 1$, TMEM24, TRIM41, and VAPB. Figure generated by GeneSpring GX after application of the 4 filtering criteria described in detail in the Materials and Methods section.

ized qPCR data from all genes tested were performed using the PROC CORR procedure of SAS.

\section{RESULTS AND DISCUSSION}

\section{ICG Selection and Evaluation}

The approach to select ICG from microarray data uncovered AP1S1, API5, PCSK2, PPP2R5B, PTBP1, QTRT1, TBK1, TMEM24, TRIM41, and VAPB as the most stable genes among $>10,000$ annotated transcripts (Table 2). These represented 10 novel, potential ICG with stable expression (ratio sample/reference $=1.0 \pm$ 0.2 ; Figure 1) throughout the entire lactation. None of the 9 ICG previously tested in bovine mammary tissue (Bionaz and Loor, 2007) were present in the list of potential porcine ICG uncovered by microarray analysis. There was larger variability among samples for these 9 ICG (ratio sample/reference $=1.27 \pm 1.25$ ) and a large difference in mRNA abundance between sample and reference for some of those ICG (e.g., GAPDH with 0.33 \pm 0.16 and RPS15A with $2.58 \pm 2.09$ ), or both.

Co-regulation among the 10 selected genes from the microarray plus the additional 9 previously tested ICG in bovine mammary (Table 2) was assessed using Inge- nuity Pathways Analysis. Ingenuity Pathways Analysis is a Web-based software that uses information from the published literature on humans and rodents (in vivo and in vitro) to generate relationships among genes or proteins. This analysis allowed identification of 10 genes without known co-regulation that served as candidates for stability analysis. Ingenuity Pathways Analysis identified co-regulation among $A C T B$, GAPDH, ITGB4BP, PCSK2, PTBP1, RPS9, RPS23, $T B K 1$, and $U X T$, which are part of complex gene networks (Figure 2). These were excluded from further analysis, with the exception of UXT and ACTB. Apparently, $U X T$ and $A C T B$ are co-regulated by MYC. In fact, MYC directly affects expression of ACTB (Grandori et al., 2005) and also binds the promoter region of $U X T$ (Mao et al., 2003). However, there is no direct evidence that MYC actively regulates $U X T$ expression in vivo. Despite these apparent limitations, which can affect pairwise comparison analysis (i.e., geNorm), we kept $A C T B$ and $U X T$ in the subsequent analysis, because $A C T B$ is one of the most widely used ICG for qPCR across cell types, tissues, and organisms, and UXT was one of the most suitable ICG in bovine mammary tissue (Bionaz and Loor, 2007). 
Table 2. Gene description, cellular location, and main function or component, or both, of the 10 genes selected as the more stable genes with $\sim 1$ sample/reference ratio among a temporal porcine mammary array data set plus 9 previously tested internal control genes (Bionaz and Loor, 2007)

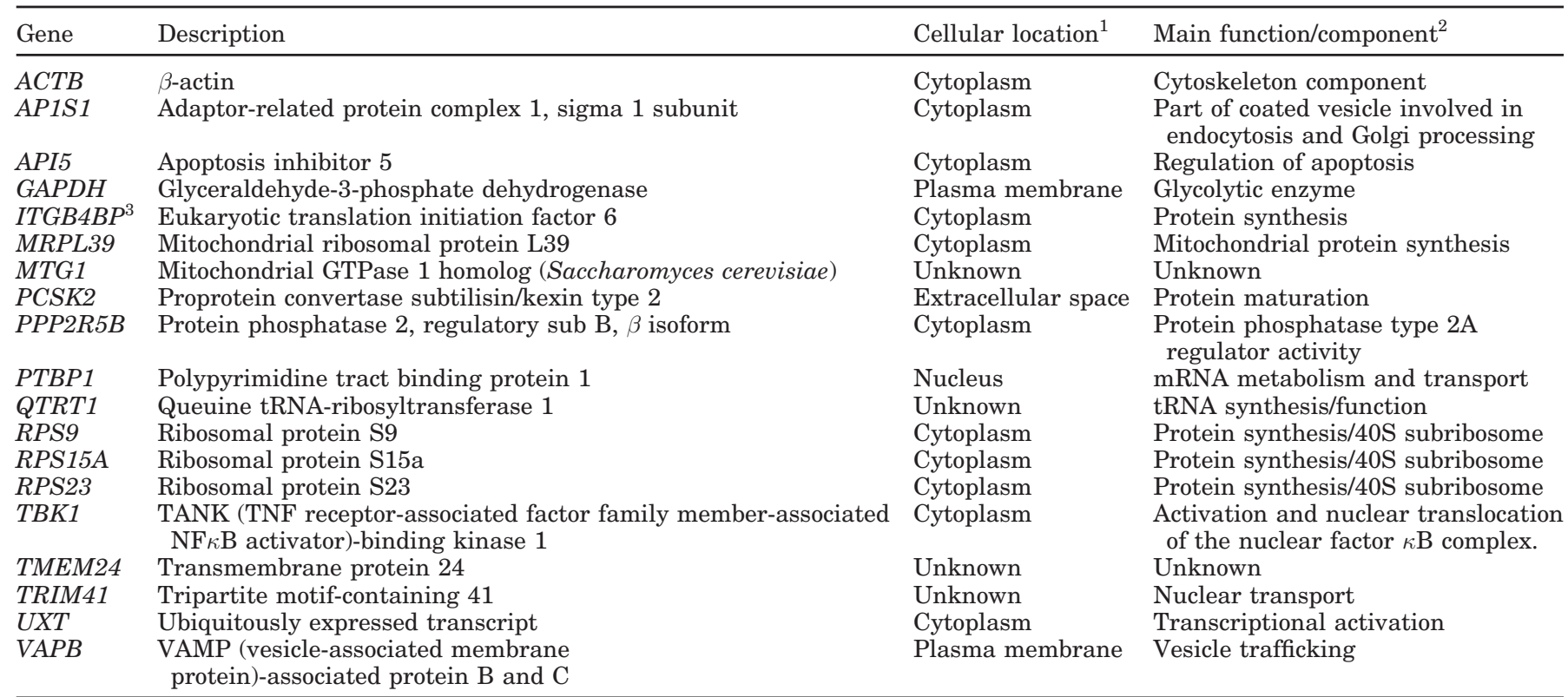

${ }^{1}$ From Ingenuity Pathway Analysis (Redwood City, CA).

${ }^{2}$ From gene description in NCBI (National Center for Biotechnology Information, 2008).

${ }^{3}$ Also denominated EIF6 in humans.

Pig-specific sequences for QTRT1and TMEM24 were not available, and sequences of Homo sapiens genes were used instead to design specific primers (accession no. NM_031209 and NM_014807.3, respectively). However, those primers were unable to amplify any cDNA. Suitable primers were designed for the remaining 8 genes (AP1S1, API5, MTG1, MRPL39, PPP2R5B, RPS15A, TRIM41, and VAPB) plus ACTB and UXT (Table 1). Among these, PPP2R5B had very low expression in pig mammary tissue (median cycle threshold = 29.5) and was not considered for subsequent analysis.

\section{ICG Expression Pattern}

All ICG tested had the same pattern of expression across the time points studied (Figure 3). There was a progressive decrease in relative mRNA abundance from -34 to 28 DIM for all of the potential ICG measured. This apparent temporal decrease in mRNA abundance parallels previous observations of ICG in bovine mammary tissue (Bionaz and Loor, 2007). In that study, it was clearly demonstrated that this trend was an artifact of the qPCR protocol, which uses equal amounts of RNA for synthesis of cDNA, and the apparent reduction of stably expressed genes throughout lactation was a consequence of a dilution of their mRNA due to the large increase in RNA synthesis of milk-specific genes (e.g., $L A L B A$ ). In support of our hypothesis, Kensinger et al. (1982) reported a sudden increase of RNA concentration in pig mammary at parturition, leading to large increases of tissue RNA/DNA ratio.

\section{ICG and Dilution Effects}

Based on the above premises and our data (Figure 3), we hypothesized that the reduction of stably expressed genes (i.e., potential ICG) in porcine mammary during lactation was apparent and could be explained by a dilution effect, as seen previously in bovine mammary (Bionaz and Loor, 2007). To verify the hypothesis, we selected 4 genes from the microarray data whose expression was not only abundant in mammary tissue but also increased markedly from farrowing through lactation: CSN1S2, FABP3, $L T F$, and $S C D$. All these genes were confirmed via qPCR to be highly expressed in lactating porcine mammary relative to nonlactating tissue (Table 3) and had an extremely large increase in expression at the onset of lactation (Figure 4). Correlation analysis revealed an inverse relationship between the expression of highly abundant genes and ICG (Table 4), particularly for CSN1S2, the most abundant transcript during lactation among the ones analyzed (Table 3). Overall, the data support the hypothesis of a dilution effect caused by a large surge in mRNA synthesis of highly abundant transcripts. Interestingly, $F A B P 3$ had a minimal effect on the dilution of stably 

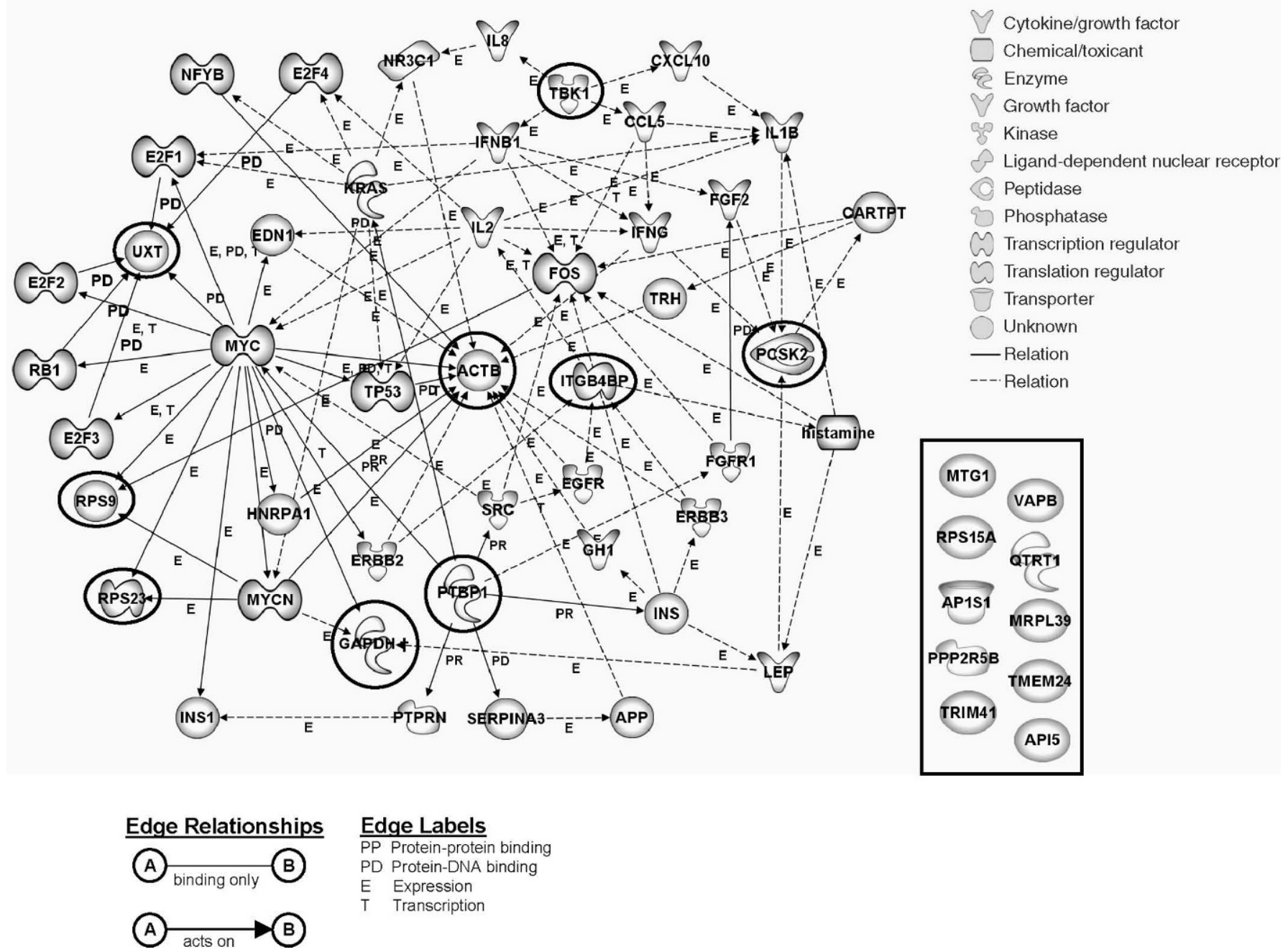

Figure 2. Known interactions that determine co-regulation (i.e., common upstream regulation) among internal control genes (ICG) under investigation. Potential ICG with known co-regulation are circled. The ICG without currently known interactions are framed in a box and were used for subsequent analysis.

expressed genes (Table 3) likely due to its relatively large mRNA abundance at -34 d relative to parturition (Table 3 ) and its behavior at 0 DIM, which corresponded with an increase in expression of some ICG (e.g., AP1S1 and $U X T$; Figures 3 and 4 ).

A significant decrease in ICG mRNA abundance, as a consequence of the dilution effect, such as a pre- vs. postpartum comparison, clearly highlights the limitation in solely relying on a temporal effect as the primary criteria in evaluating the appropriateness of ICG. Thus, an alternative method is essential to overcome this limitation. The pairwise comparison, previously demonstrated to be suitable to identify ICG stability in bovine mammary (Bionaz and Loor, 2007), was applied in this study. The pairwise comparison method is based on the fact that all genes with stable expression are affected to a similar extent by errors during the steps from RNA extraction to qPCR analysis. Therefore, the expression ratios among them should remain constant across samples (Vandesompele et al., 2002). The most stable genes (i.e., lowest $\mathrm{M}$ value) were VAPB and MRPL39, whereas $A P 1 S 1$ and MTG1 were the least stable, followed by $U X T$ and ACTB (Figure 5). A low reliability of ACTB as ICG has been reported previously by others in cells (Glare et al., 2002) and bovine mammary tissue (Bionaz and Loor, 2007). In contrast, Bionaz and Loor (2007) reported $U X T$ as an ideal ICG among those tested. Clearly, ICG in the same tissue from one organism might not be suitable for $\mathrm{qPCR}$ normalization in other species. 

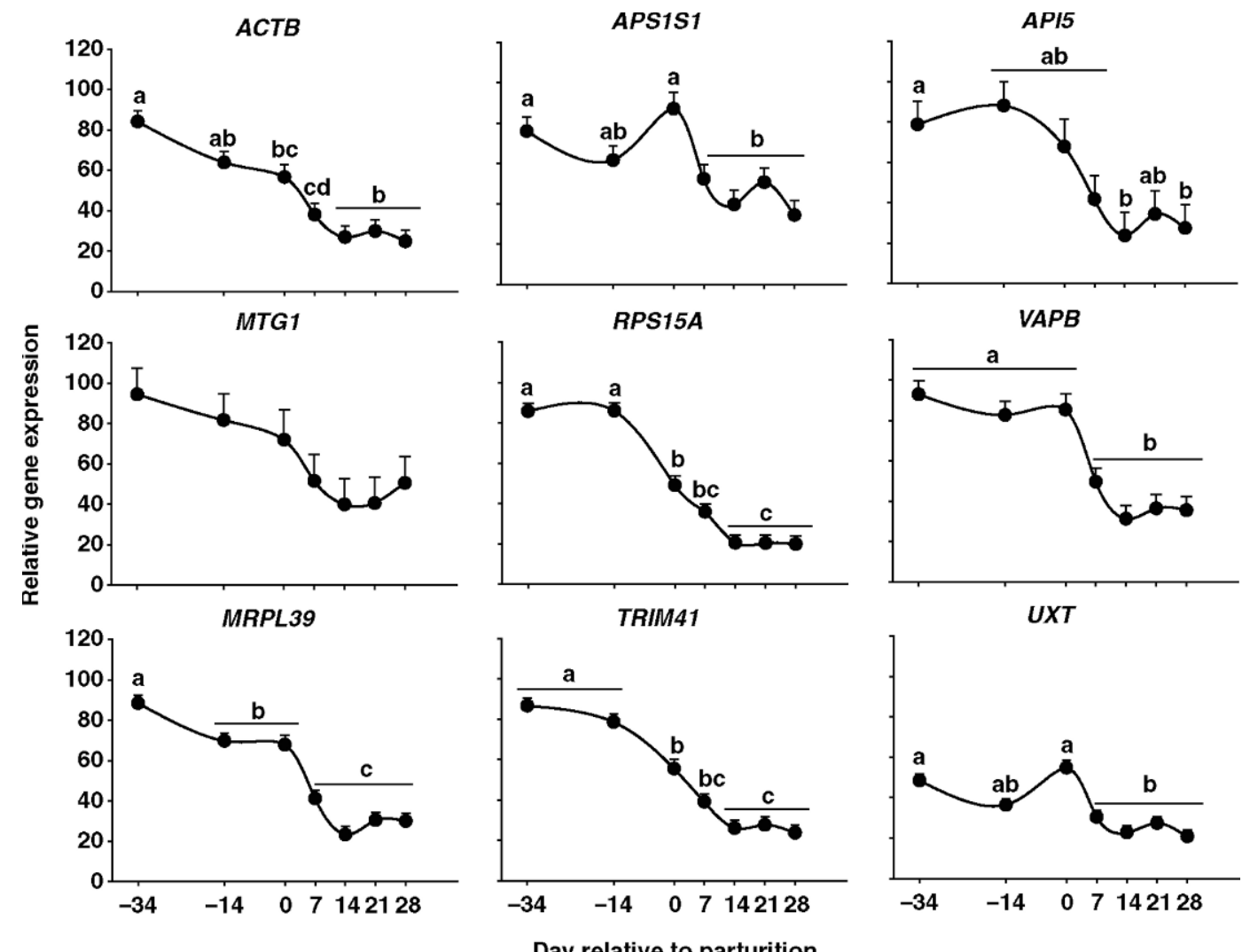

Figure 3. The mRNA expression patterns (mean \pm overall SEM) of potential internal control genes. Data shown are from transformed cycle threshold values with a standard curve. Time effect was $P \leq 0.05$ for all genes. Different letters denote time effects among time points.

Table 3. Slope and coefficient of determination of the standard curve $\left(\mathrm{R}^{2}\right)$, efficiency $(\mathrm{E})$, median cycle threshold or number of cycles required for fluorescent signal to cross the threshold (Ct), and mRNA abundance of the measured transcripts

\begin{tabular}{|c|c|c|c|c|c|c|}
\hline \multirow[b]{2}{*}{ Gene } & \multirow[b]{2}{*}{ Slope $^{1}$} & \multirow[b]{2}{*}{$\mathrm{R}^{2}$} & \multirow[b]{2}{*}{$\mathrm{E}^{2}$} & \multirow{2}{*}{$\begin{array}{c}\text { Median } \\
\mathrm{Ct}\end{array}$} & \multicolumn{2}{|c|}{ mRNA abundance (DIM) ${ }^{3}$} \\
\hline & & & & & -34 & 28 \\
\hline$A C T B$ & -3.34 & 0.993 & 1.99 & 22.4 & 1.0 & 1.0 \\
\hline API5 & -3.05 & 0.998 & 2.13 & 22.5 & 0.8 & 1.2 \\
\hline$A P S 1 A 1$ & -3.23 & 0.998 & 2.04 & 21.7 & 1.1 & 2.3 \\
\hline MRPL39 & -3.05 & 0.994 & 2.13 & 20.6 & 3.1 & 3.7 \\
\hline MTG1 & -3.12 & 0.998 & 2.09 & 22.8 & 0.6 & 0.9 \\
\hline RPS15A & -3.35 & 0.997 & 1.99 & 16.3 & 64 & 59 \\
\hline TRIM41 & -2.83 & 0.999 & 2.26 & 22.0 & 1.2 & 1.6 \\
\hline$U X T$ & -2.78 & 0.989 & 2.29 & 25.5 & 0.1 & 0.2 \\
\hline$V A P B$ & -3.12 & 0.983 & 2.09 & 21.4 & 1.7 & 2.7 \\
\hline CSN1S2 & -3.32 & 0.994 & 1.99 & 12.5 & 0.6 & 9,467 \\
\hline$F A B P 3$ & -3.40 & 0.998 & 1.97 & 14.4 & 63 & 402 \\
\hline$L T F$ & -4.07 & 0.998 & 1.76 & 17.6 & 4.5 & 26 \\
\hline$S C D$ & -3.41 & 0.996 & 1.96 & 16.4 & 4.4 & 206 \\
\hline
\end{tabular}

${ }^{1}$ Slope generated by 6 -point standard curve.

${ }^{2}$ Efficiency $=10^{(-1 / \text { slope })}$.

${ }^{3}$ The mRNA abundance is relative to ACTB. Abundance $=1 / \mathrm{E}^{\text {(median } \mathrm{Ct})}$. 

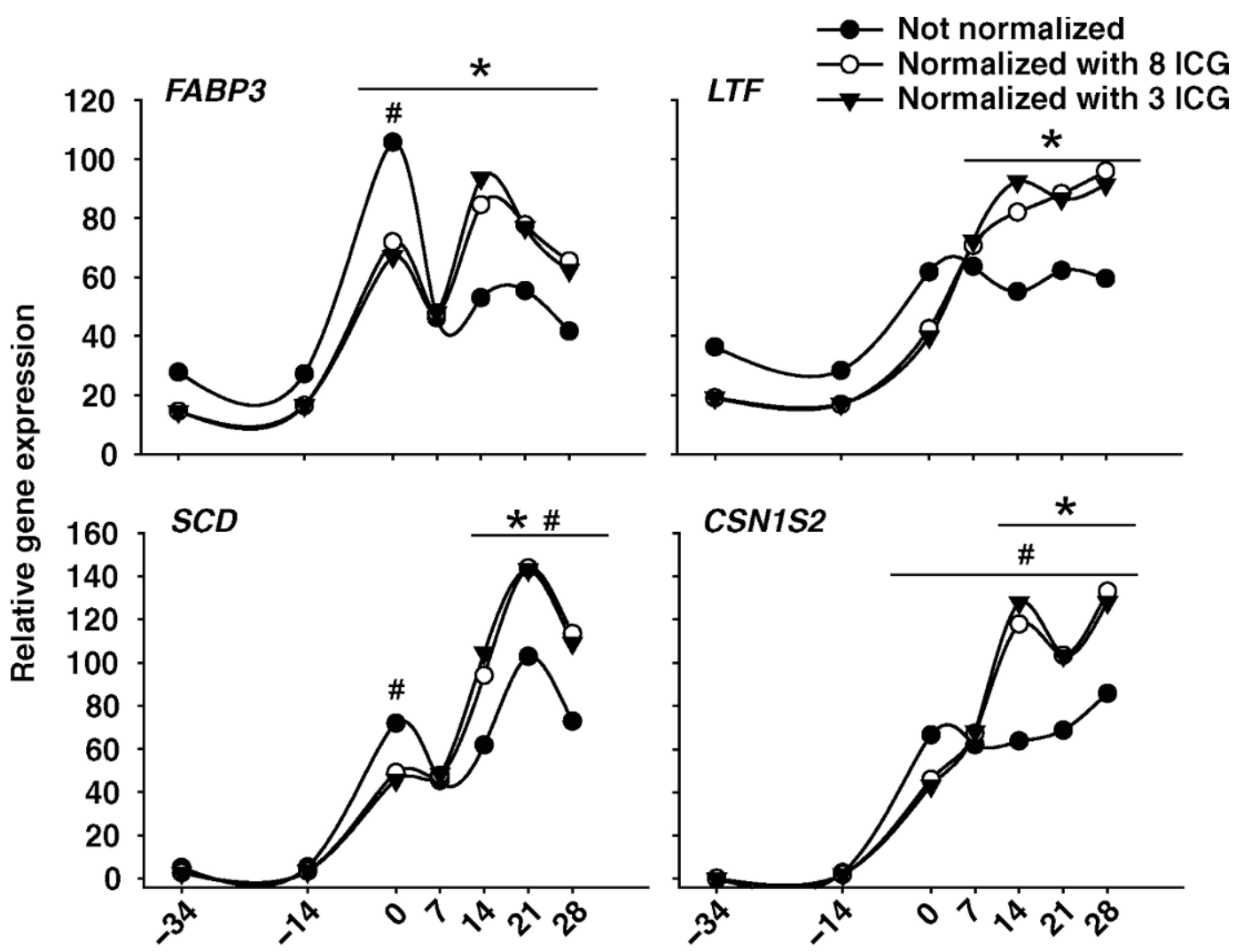

Day relative to parturition

Figure 4. Patterns of $C S N 1 S 2, F A B P 3, L T F$, and $S C D$ before and after normalization using normalization factor calculated with the geometrical mean of 3 or 8 most stable genes from geNorm analysis. Time effect was $P<0.01$ for all the genes. The SEM for genes normalized with 3 ICG were as follows: $C S N 1 S 2=18.9 ; F A B P 3=6.2 ; L T F=9.3 ; S C D=14.2$. The symbols $*$ and \# denote significant $(P<0.05)$ effects relative to -34 DIM for normalized (3 ICG) and not normalized data, respectively.

\section{Considerations for Selecting Optimal Number of ICG}

A minimum of 3 genes should be used as ICG (Vandesompele et al., 2002). Results showed a large decrease in the variation of pairwise expression ratios when using 3 genes instead of 2, for instance, from $0.17-$ pairwise VAPB and MRPL39 (top panel of Figure 5) to 0.065 in V2/3 (lower panel in Figure 5). Thus, addition of the subsequent most stable gene increased the reliability of NF. The use of 4 genes instead of 3 re- sulted in a small increase in stability ( 0.065 vs. 0.060$)$. The maximum reliability of $\mathrm{NF}$ would have been obtained using 8 of 9 genes tested $(\mathrm{M}=0.044$ at $\mathrm{V} 7 / 8$, Figure 5 lower panel). Based on both practicality and $\mathrm{M}<0.10$, the limit previously set as acceptable (Bionaz and Loor, 2007), use of the 3 most stable genes (i.e., $V A P B, A P I 5$, and MRPL39) to calculate the NF was highly reliable.

To our knowledge, VAPB, API5, and MRPL39 have never been used as ICG. The description, main function, and cellular location of all genes tested are re-

Table 4. Pearson correlation between nonnormalized qPCR data of CSN1S2, LTF, FABP3, and SCD with nonnormalized qPCR data of potential internal control genes (ICG) in pig mammary tissue across all time points analyzed ${ }^{1}$

\begin{tabular}{lcccccccrr}
\hline Gene & ACTB & APS1S1 & API5 & MRPL39 & MTG1 & RPS15A & TRIM41 & UXT & VAPB \\
\hline CSN1S2 & -0.69 & -0.42 & $-\underline{0.60}$ & $-\underline{-0.69}$ & -0.39 & -0.79 & -0.81 & -0.43 & -0.62 \\
FABP3 & -0.15 & 0.43 & $-\overline{0.06}$ & $-\overline{0.03}$ & 0.03 & -0.26 & -0.22 & 0.40 & -0.11 \\
LTF & -0.56 & -0.16 & $\underline{-0.47}$ & $-\overline{0.53}$ & -0.40 & -0.66 & -0.59 & -0.22 & $-\underline{0.45}$ \\
SCD & -0.54 & -0.15 & $\underline{-0.46}$ & $\underline{-0.55}$ & -0.28 & -0.70 & -0.68 & -0.23 & $-\underline{-0.49}$ \\
\hline
\end{tabular}

${ }^{1}$ Comparisons for the best ICG are underlined ( $>0.38$ corresponding to $P \leq 0.05$ ). 

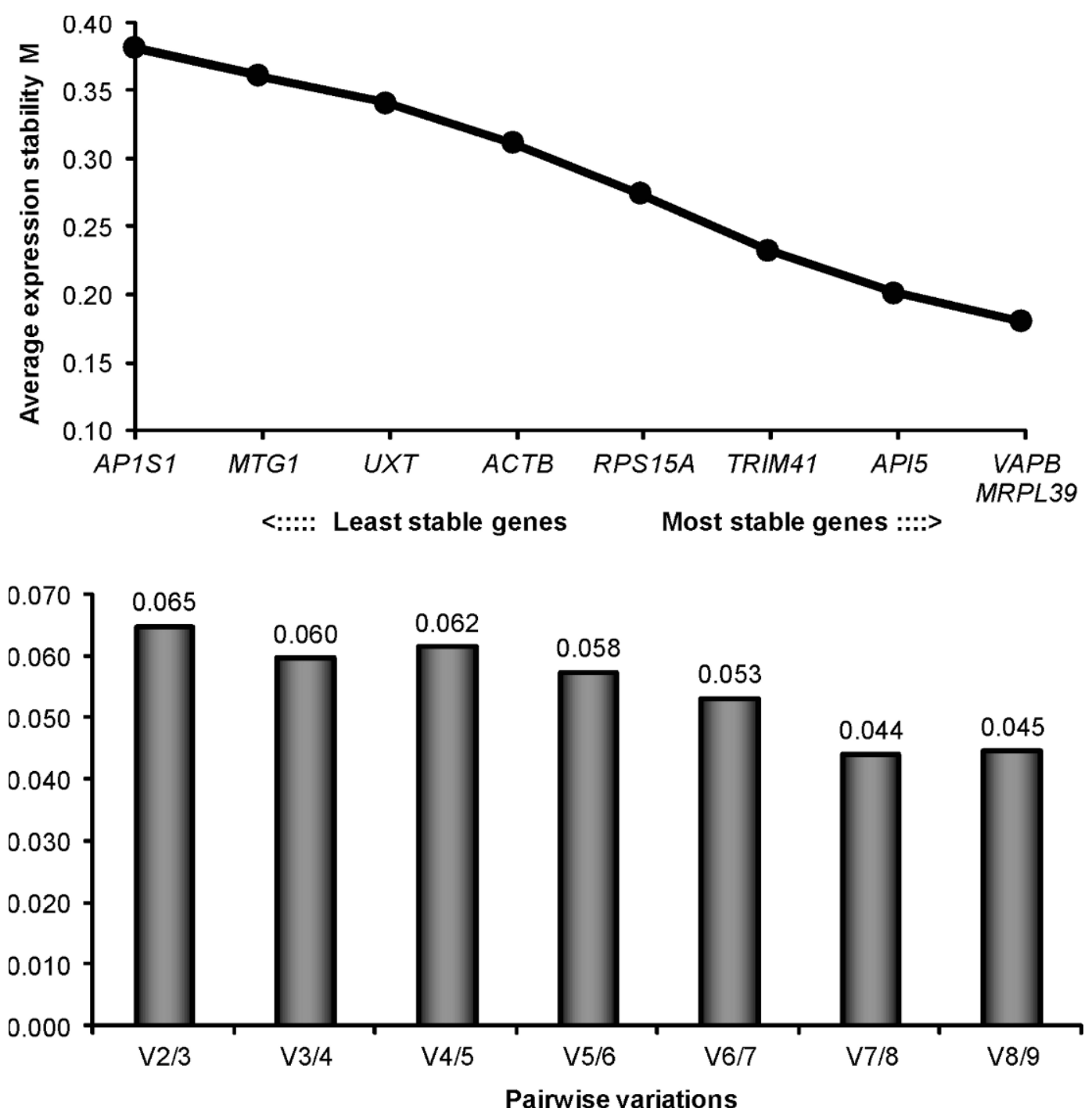

Figure 5. Top panel: geNorm results for the average expression ratio stability (M) of potential internal control genes (ICG) calculated via pairwise comparison. Bottom panel: determination of optimal ICG number for normalization. $\mathrm{y}$-axis $=$ pairwise variation $\mathrm{V}\left(\mathrm{V}_{\mathrm{n}} / \mathrm{n}+1\right)$ between the normalization factors $\mathrm{NF}_{\mathrm{n}}$ and $\mathrm{NF}_{\mathrm{n}+1}$; $\mathrm{x}$-axis = comparison between the use of $n$ or $n+1$ genes to calculate the normalization factor.

ported in Table 2. Vesicle-associated membrane protein $(V A P B)$ encodes a membrane protein found in plasma membranes and intracellular vesicle membranes with a likely involvement in vesicle trafficking (Teuling et al., 2007). Apoptosis inhibitor-5 (API5) is a protein with potent antiapoptotic activity and with a crucial role in tumor cell survival (Morris et al., 2006). Mitochondrial ribosomal protein L39 (MRPL39) is a nuclear gene coding for a constituent of mitochondrial ribosomes, which are essential for the translation of mitochondrial genes mostly involved in oxidative phosphorylation (O'Brien, 2003).

The large discrepancy between nonnormalized and normalized qPCR data of CSN1S2, FABP3, LTF, and $S C D$ highlights the importance of normalization (Fig- ure 4). Comparing normalized expression using 8 vs. 3 most stable genes (Figure 5) confirmed that there was minimal difference in normalized qPCR results by having 5 additional ICG to calculate NF (i.e., stability increased minimally). Thus, using only the 3 most stable genes for normalization was most appropriate, and we suggest it is the minimal number of ICG that should be used to improve precision and relevance of qPCR data.

\section{CONCLUSIONS}

Results confirmed that a simple statistical analysis of mRNA data would have rejected our candidate ICG as inappropriate because of an apparent temporal ef- 
fect on their expression. In addition, we showed that use of the same ICG from one organism might not be suitable for qPCR normalization in other species. This point is particularly important due to the extensive use of $A C T B$ and GAPDH in the livestock scientific community. We demonstrated that the apparent temporal decrease in ICG between pregnancy through lactation was a consequence of the dilution effect caused by large increases in mRNA synthesis of tissue-abundant genes (e.g., CSN1A2, $L T F$, and $S C D$ ). Use of the pairwise comparison method was suitable for selecting reliable ICG. We identified MRPL39, API5, and VAPB as novel ICG for qPCR in temporal studies of pig mammary tissue.

\section{ACKNOWLEDGMENTS}

Partial support for the gene expression work was provided by the Illinois Agric. Exp. Stn. as part of Hatch Project 538-327, under project no. ILLU-350344 .

\section{REFERENCES}

Bionaz, M., and J. J. Loor. 2007. Identification of reference genes for quantitative real-time PCR in the bovine mammary gland during the lactation cycle. Physiol. Genomics 29:312-319.

Fleige, S., and M. W. Pfaffl. 2006. RNA integrity and the effect on the real-time qRT-PCR performance. Mol. Aspects Med. 27:126-139.

Genome Browser Gateway. 2008. http://genome.ucsc.edu/ Accessed Jan. 23, 2008.

geNorm. 2008 http://medgen.ugent.be/ jvdesomp/genorm/ Accessed Feb. 12, 2008.

Glare, E. M., M. Divjak, M. J. Bailey, and E. H. Walters. 2002. $\beta$ Actin and GAPDH housekeeping gene expression in asthmatic airways is variable and not suitable for normalising mRNA levels. Thorax 57:765-770.

Grandori, C., N. Gomez-Roman, Z. A. Felton-Edkins, C. Ngouenet, D. A. Galloway, R. N. Eisenman, and R. J. White. 2005. c-Myc binds to human ribosomal DNA and stimulates transcription of rRNA genes by RNA polymerase I. Nat. Cell Biol. 7:311-318.

Hacker, R. R., and D. L. Hill. 1972. Nucleic acid content of mammary glands of virgin and pregnant gilts. J. Dairy Sci. 55:1295-1299.

Hurley, W. L., R. M. Doane, M. B. O’Day-Bowman, R. J. Winn, L. E. Mojonnier, and O. D. Sherwood. 1991. Effect of relaxin on mammary development in ovariectomized pregnant gilts. Endocrinology 128:1285-1290.

Kensinger, R. S., R. J. Collier, F. W. Bazer, C. A. Ducsay, and H. N. Becker. 1982. Nucleic acid, metabolic and histological changes in gilt mammary tissue during pregnancy and lactogenesis. J. Anim. Sci. 54:1297-1308.

Kim, S. W., W. L. Hurley, I. K. Han, and R. A. Easter. 1999. Changes in tissue composition associated with mammary gland growth during lactation in sows. J. Anim. Sci. 77:2510-2516.

Loor, J. J., H. M. Dann, R. E. Everts, R. Oliveira, C. A. Green, N. A. Guretzky, S. L. Rodriguez-Zas, H. A. Lewin, and J. K. Drackley. 2005. Temporal gene expression profiling of liver from periparturient dairy cows reveals complex adaptive mechanisms in hepatic function. Physiol. Genomics 23:217-226.

Mao, D. Y., J. D. Watson, P. S. Yan, D. Barsyte-Lovejoy, F. Khosravi, W. W. Wong, P. J. Farnham, T. H. Huang, and L. Z. Penn. 2003. Analysis of Myc bound loci identified by CpG island arrays shows that Max is essential for Myc-dependent repression. Curr. Biol. $13: 882-886$

Morris, E. J., W. A. Michaud, J. Y. Ji, N. S. Moon, J. W. Rocco, and N. J. Dyson. 2006. Functional identification of Api5 as a suppressor of E2F-dependent apoptosis in vivo. PLoS Genet. 2:e196.

National Center for Biotechnology Information. 2008. http:// www.ncbi.nlm.nih.gov/blast/Blast.cgi Accessed Jan. 10, 2008.

O'Brien, T. W. 2003. Properties of human mitochondrial ribosomes. IUBMB Life 55:505-513.

Reinhardt, T. A., and R. L. Horst. 1999. $\mathrm{Ca}^{2+}$-ATPases and their expression in the mammary gland of pregnant and lactating rats. Am. J. Physiol. 276:C796-C802.

Teuling, E., S. Ahmed, E. Haasdijk, J. Demmers, M. O. Steinmetz, A. Akhmanova, D. Jaarsma, and C. C. Hoogenraad. 2007. Motor neuron disease-associated mutant vesicle-associated membrane protein-associated protein (VAP) B recruits wild-type VAPs into endoplasmic reticulum-derived tubular aggregates. J. Neurosci. 27:9801-9815.

Tramontana, S., A. Sharma, M. Bionaz, D. E. Graugnard, E. A. Cutler, R. E. Everts, S. L. Rodriguez-Zas, W. L. Hurley, and J. J. Loor. 2007. MammOmics ${ }^{\mathrm{TM}}$ in Sus scrofa: Uncovering genomic adaptations underlying mammary development during pregnancy and lactation. Page 77 in Proc. Convergence of Genomics and the Land Grant Mission: Emerging Trends in Application of Genomics in Agricultural Research. Purdue University, West Lafayette, IN.

Valasek, M. A., and J. J. Repa. 2005. The power of real-time PCR. Adv. Physiol. Educ. 29:151-159.

Vandesompele, J., K. De Preter, F. Pattyn, B. Poppe, N. Van Roy, A. De Paepe, and F. Speleman. 2002. Accurate normalization of real-time quantitative RT-PCR data by geometric averaging of multiple internal control genes. Genome Biol. 3:RESEARCH0034. 